\title{
تطوير المادة التعليمية بخريطة المفاهيم
}

\section{ABSTRACT}

Rahmawati, Rina Dian. Teaching Materials Development of Mind Map

Keywords: Teaching Materials Development, Mind Map

The Mind Map of Understanding is a wonderful tool that helps the mind to think systematically. Is very simple. The mapping of concepts is the process and the method of entering the information into the mind, and to take information from the mind. The map became concepts in the area of learners' access to and development of information. The concept map allows for several purposes: examining what the student knew, learning how to teach, expressing non-concepts and evaluation

$$
\text { رحمواتي، رين ديان }
$$

تطوير المادة التعليمية ،خريطة المفاهيم

خريطة المفاهم هى أداة عجيبة تساعد العقل للتفكير المنسق المنظم. هي بسيطة جدا. وأما رسم الخريطة المفاهيم هو العملية و الطريقة السهلى لإدخال المعلومات إلى العقل، ولأخذ المعلومات من العقل. وأصبحت الخريطة المفاهيم في مجال توصل المتعلمين للمعلومات وتطويرها. فبواسطة الخريطة المفاهيم يتضح البناء المعري والمهاري لدى المتعلم في فهم النصوص العربي.في التعليم خريطة المفاهيم مسموح للتطبيق لعدة أغراض منها: فحص ما عرفه الطالب، معرفة كيفية التعليم، التعبير غير المفاهيم, أدوات التقويم.

\section{أ- مفهوم المادة التعليمية}

يقصد بالمادة التعليمية كما قال بعض الخبراء هى كل المواد المكتوبة أو غير المكتوبة التي

تستخدم لمساعدة المعلم أو المدرب في العملية التعليمية في الفصل. وقال رأي أخر المادة

التعليمية هى المواد التي ترتب بنظام خاص مكتوبة أو غير مكتوبة، لكي يمكن التلاميذ للتعلم

في الفصل. وقيل أيضا المادة التعليمية هى المعلومات، أو الآلات والنصوص التي يحتاجها المعلم 


\section{Rina Dian Rahmawati}

أو المدرب لتصميم وتنفيذ التعليمية. وقال فانين المادة التعليمية هى المواد أو المواد التعليم التي ترتب بالنظام الخاص يستخدمها المعلم والمتعلم في العملية التعليمية.

ومن هؤلاء التعريفات، نستنبط الفهم على أن المواد التعليمية هى كل المواد ( المعلومات،

الآلات، والنصوص) التي ترتب بنظام خاص لتصوير الوحدة الكفائية يستوليها المتعلم

ومستخدمة في العمليية التعليمية مؤسسا بالأهداف المتصممة وتنفيذ التعليمية'.

ومن بين الكتب التعليمية جمعاء ، تقف كتب تعليم اللغات فوق أعلى درجة من

درجات الأهمية، كما تعتبر أسمى أداة من أدوات التثقيف و تحقيق التعاهم بين أفراد المجتمع، و

بينهم و بين غيرهم من أفراد المجتمعات الأخرى. وهنا تبرز القيمة الكبيرة لما نبذله الشعوبة في

سبيل تعليم لغاتها لأبناء غيرها من الشعوب. وهنا أيضا تكمن الدوافع الحقيقية وراء استنهاض

الهمم وبذل الجهود نهو تأليف كتب لتعليم العربية في السنوات الأخيرة. إن الأمر ليس مجرد

حرص على تدريب الآخرين على نطق أصوات العربية، أو حفظ الكلماقا، أو تعرف

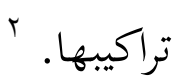

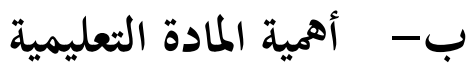

أهمية المادة التعليمية ينقصم الي الأهداف والفائدة و الوظيفة هى":

$$
\text { 1. أهداف المادة التعليمية }
$$

17.

${ }^{1}$ Andi Prastowo, Panduan Kreatif Membuat Bahan Ajar Inovatif, (Jogjakarta:Diva Press, 2013), hlm167.

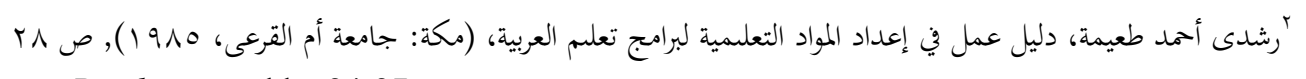

${ }^{3}$ Andi Prastowo, Panduan...... hlm 24-27. 


$$
\begin{aligned}
& \text { (1) ( ) مساعدة المتعلم في التعليم } \\
& \text { r) استعداد أنواع المادة التعليمية حتى لا يدخل الملول والشأم. } \\
& \text { r) السهل للمتعلم في عملية التعليم } \\
& \text { ع) أن تكون عملية التعليم ممتعة } \\
& \text { ب ا ب ائد المادة التعليمية }
\end{aligned}
$$

فوائد للمعلم والمتعلم، للمعلم المادة التعليمية تساعده في عملية التعليم، لترقية

درجاته، لزيادة راتبه في عملية التعليم. وإما للمتعلم، عملية التعليم متعة له، أكثر فرصة

للمتعلم يتعلم ذاتيا دون رعاية المعلم.

$$
\text { r. ب. وظيفة المادة التعليمية }
$$

وظيفة المادة التعليمية ينقسم إلى قسمين :

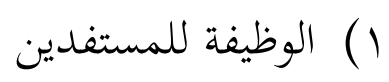

والمقصود بها الوظيفة لدى المعلم والمتعلم، وللمعلم توفير الوقت في التعليم،

وتغيير دور المعلم على أن يكون الميسر، ترقية عملية التعليم عل أن تكون فعالا

واتصالا، ودليلا وألة القياس في نجاح تحصيل التعليم. وإما الوظيفة للمتعلم، المتعلم

يستطيع أن يتعلم ذاتيا دون المعلم، المتعلم يتعلم على ماشاء وقت ومكانا، مناسبة

على كل سرعته في التعليم، المتعلم يرتب دروسه على حسب ميوله، المساعة

$$
\text { للتلاميذ لترقية كفاءقم، ودليلا له في كل أنشطته التعليمية. }
$$




\section{Rina Dian Rahmawati}

\section{r) الوظيفة على الإسترابتية المستخدمة}

وظيفة المادة التعليمية هنا يشمل على ثلاثة أنواع،وهى الكلاسيكي والفردي<smiles>C=[As][As]</smiles>

\section{ج- أساسيات إعداد مواد التعليمية}

يعتبر إعداد المواد التعليمية واختيارها من أصعب الأمور التي تواجه المسؤوليين عن

البرامج التعليمية، وذالك لأن المتعلمين يحتاج لمجموعة من المعايير والضوابط والشروط

والموصفات التي بدوها تصبح كلتا هما عملية غير عملية. إن علمية إعداد المواد التعليمية هي

في الأساس عملية تربوية، إذن فهى عملية تقوم على مجموعة من الأسس والمبادئ المستمدة

من المجالاتالتي ينبغي أن تعالج في المواد التعليمية.

وعلى أية حال هناك حاجة شديدة إلى مجموعة من المبادئ والأسس والمنطلقات،

وطريقة إعداد المواد التعليمية لتعليم اللغة العربية لغير الناطقين بها بشكل عملي مقبول. ومن

المبادئ والأسس والشروط التي تعيين على إعداد المواد التعليمية وعلى تقويمها على الجوانب

الأربعة : هى الجانب النفسي، والجانب الثقافي، والجانب التربوي، والجانب اللغوي؛.

\section{د- الخطوات لإعداد المواد التعليمية}

1. ت تحليل الاحتياجات للمادة التعليمية

"عممود كامل الناقة ورشدي أممد طعيمة، الكتاب الأساسي لتعلم اللغة العربية للناطقين بلغة أخرى( مكة المكرمة: جامعة أم القرى، 
ويقصد به هو مرحلة الأولى لتأليف المادة التعليمية يشمل فيه تحليل المنهج، تحليل المصادر التعليمية، وتعيين الموضوع للمادة التعليمية، وهذه العملية لاينفصل بعضها

$$
\begin{aligned}
& \text { ببعض - } \\
& \text { Y. ههم خصائص اختيار المصادر التعليمية } \\
& \text { خصائص اختيار المدة التعليمية تنقسم إلى قسمين: } \\
& \text { ( ) خصائص العامة تشمل على } \\
& \text { أ) الاقتصادية } \\
& \text { ب) سهل }
\end{aligned}
$$

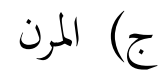

$$
\begin{aligned}
& \text { (Y ) خصائص الضاصة } \\
& \text { أ) مصادر التعليمية أن تكون دافعة للتلاميذ } \\
& \text { ب) مصادر التعليمية أن تكون هدفا للتعليم } \\
& \text { ج) مصادر التعليمية أن تكون للبحث } \\
& \text { د) مصادر التعليمية أن تكون لعلاج المشكلات } \\
& \text { هـ) مصادر التعليمية أن تكون آلة وطريقة واسترابتية لإيصال المعلومات. } \\
& \text { r. ترتيب خرائط المادة التعليمية }
\end{aligned}
$$




\section{Rina Dian Rahmawati}

ع. ـ فهم نظام المادة التعليمية

خريطة المفاهيم

ا

وأكد أوسوبيل Ausubel على المعلم أن يعرف المفاهيم التي يملكها الطالب لكي

التعليم الفهي يجري. لكن أوسوبيل لم يستعد للمعلم آداة خاصة ليستفيدها لمعرفة ما عرفه

الطلالب. وقال نوفاق " هذه يمكن أن أدها بمساعدة خريطة المفاهيم أو تخطيطة الفهم، رأيه

تبني على النظرية التعليم لدي أوسوبيل"'. الخريطة المفاهيم هي أداة عجيبة تساعد العقل

للتفكير المنسق المنظم. هي بسيطة جدا. واما رسم الخريطة هو العملية والطريقة السهلى

لإدخال المعلومات الى العقل، ولأخذ المعلومات من العقل. وهذه الطريقة طريقة ابتكارية

وابداعية وفعالة لكتابة الأفكار. v

خريطة المفاهيم عبارة عن أشكال مرئية لأخذ الملاحظات، يمكن أن يقوم بها شخص

واحد بجموعة من الناس. ويوجد في قلب الشكل فكرة مركزية أو صورة. ويتم بعد ذلك

استكشاف هذه الفكرة عن طريق الفروع التي تمثل الأفكار الرئيسية، والتي تتصل جميعا

بالفكرة المركزية

${ }^{5}$ AndiPrastowo, Panduan .......hlm50-65.

${ }^{6}$ RatnaWilisDahar, Teori-TeoriBelajar\&Pembelajaran , (Jakarta : Erlangga,2006), hlm 106-109

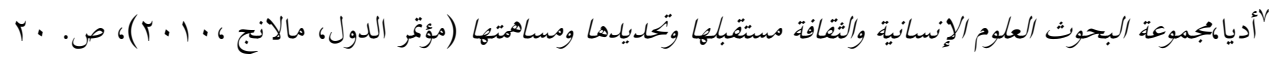

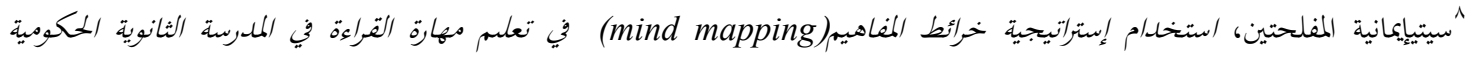

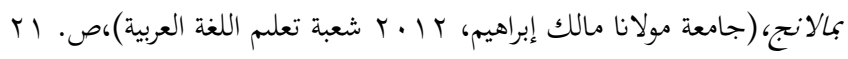

110 | Dinamika Vol. 2, No. 2, Desember 2017 
تطور خريطة المفاهيم لانكشاف المعرفي لدى طلاب ومعرفها، إما المعلم أو المتعلم ينبغي أن يعرف ما عرفه المعلم. ولو كانت خريطة المفاهيم لايؤدى إلى تصوير المفاهيم المناسبة والمتكاملة محا يعرفها المتعلم، لكن خريطة المفاهيم هى المدخل الذي يفتح للأدء ومسموح للمعلم والتمعلم لتطويره . r ب. أساسيات خريطة المفاهيم

توجد ثلاث آراء في النظرية التعليم للأوسوبيل التي تبني خريطة المهاهيم وهى: 1). البنية المعرفيية مرتبة بالمفاهيم والحصة الأشمل والأخص متكاملا.

r). المفاهيم الموجودة في البنية المعرفية التمييز والتقدمي، أي التعليم الفهمي هو عملية استمرارية على أن المفاهيم الجديدة تترقى بوجود المواصلة الحصة. إذا المفاهيم لا ينتهي

$$
\text { لدراستها، لكن لايزال يدرسها وتصميمها حتي أن يكون شرحا وتمييزا. }
$$

ب) المناسبة المتكاملة هى الأساس للتعليم لأن التعليم الفهمي تترقى بمعرفة الاتصال الجمديدة بعضه ببعض آخر.

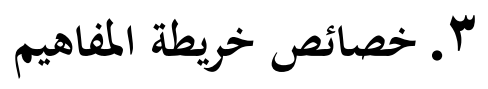

تتميز خريطة المفاهيم بعدة خصائص تميزها عن غيرها من أنواع المخططات الأخرى: ا ـ أها هرمية ومنظمة: تتميز خرائط المفهوم بسمة الهرمية ، وتعني الهرمية أن المفاهيم الأكثر شمولا تأتي في قمة الخريطة وتعلو على المفاهيم والقضايا الأقل شمولا والأكثر خصوصية . وترتسم صورة الهرمية في ضوء العلاقات التي يلاحظها معد الخريطة بين المفاهيم 


\section{Rina Dian Rahmawati}

المستهدفة بالتعلم.ويتيح البناء الهرمي للخريطة إمكانية اندماجها مع خرائط مفهومية

أخرى لإعطاء خريطة أوسع وأكبر تبرز الصورة الشمولية التكاملية لموضوع معين.

Y. أها مترابطة ومفسّرة : فهناك ترابط بين المفاهيم والأفكار والقضايا المذكورة في الخريطة

وهذا الترابط يكون عبر الوصلات الخطية والأسهم التي تصاحبها عبارات تفسر هذه

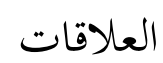

ب. أها تكاملية: حيث أن المفاهيم والأفكار والقضايا والأمثلة المذكورة ضمن الخريطة تعمل

$$
\text { لتتكامل في شرح موضوع محدد وبيان محتوياته وجوانبه المختلفة }
$$

ع. أها مفاهيمية : أي أفها تدور وتتمركز حول مفهومات وأفكار رئيسية يندرج تحتها عدد

$$
\begin{aligned}
& \text { من المفهومات والأفكار الفرعية والأمثلة .فوحدة البناء هي المفاهيمج } \\
& \text { و تتميز الخريطة المفاهيم بقدرتا السريعة يعني }
\end{aligned}
$$

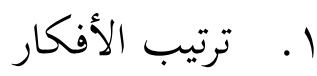

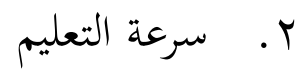

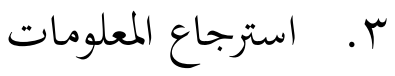

ولا يقتصر استخدام الخريطة علي الطلاب في المدرسة أو العملية التعليمية فقط، ولكنه يشمل

$$
\begin{aligned}
& \text { شؤون الحياة المختلفة فهي محكن أن تستخدم في : } \\
& \text { 1. الدراسة والعمليات التعليمية }
\end{aligned}
$$

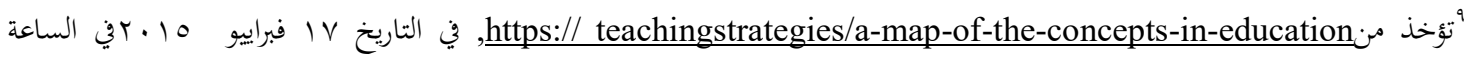


تطوير المادة التعليمية بخريطة المفاهيم

r ب المحادثات بين الأفراد

$$
\begin{aligned}
& \text { r. التخطيط في مجالات مختلفة } \\
& \text { ع. اعداد وكتابة المقالات } \\
& \text { ه. 'الاجتماعات' }
\end{aligned}
$$

ع. فوائد خريطة المفاهيم

$$
\begin{aligned}
& \text { في التعليم خريطة المفاهيم مسموح للتطبيق لعدة أغراض منها: } \\
& \text { ( ) فحص ما عرفه الطالب } \\
& \text { ( ) معرفة كيفية التعليم } \\
& \text { ب) (ب التعبير غير المفاهيم } \\
& \text { ع) أدوات التقويم؟ }
\end{aligned}
$$

خريطة المفاهيم يستفد بها المعلم في عدة بجال منها:

$$
\begin{aligned}
& \text { () التحطيط } \\
& \text { Y) الاتصال } \\
& \text { ب) إبداعي و توفير الوقت } \\
& \text { צ ) معالجة المشكلات } \\
& \text { 0) ابتحاه الاهتمام }
\end{aligned}
$$

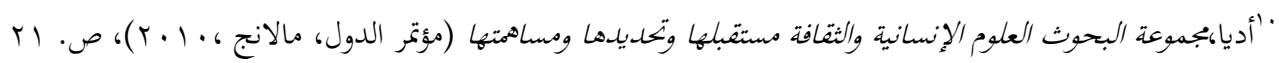

${ }^{11}$ RatnaWilisDahar, Teori-TeoriBelajar ......, hlm111 


\section{Rina Dian Rahmawati}

$$
\begin{aligned}
& \text { 7) الترتيب والتفسير للفكرات } \\
& \text { (V } \\
& \text { ^) سرعة التدريس والفعالة } \\
& \text { 9) مشاهدة الصورة المتكاملة'r } \\
& \text { •. تصميم خريطة المفاهيم }
\end{aligned}
$$

خريطة المفاهيم لها دور مهم في التعليم الفهم، لذا على كل التلاميذ يقدر على تصميم خريطة

$$
\begin{aligned}
& \text { المفاهيم. والخطوات التي تتابعها في التصميم كما يلي : } \\
& \text { ا ل. اختر المقروءة من الكتاب الدراسي }
\end{aligned}
$$

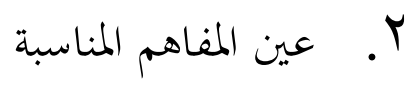$$
\text { "r. رتب المفاهيم من الشمول إلى غير الشمول أو الأمثال }
$$$$
\text { ع. ـرتب المفاهيم على القرطاس من المفاهيم الشمول اقصى إلى المفاهيم الأدين }
$$$$
\text { •. صل المفاهيم بلكلمات أو الكلمات المتصلة" }
$$

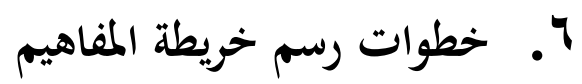

$$
\begin{aligned}
& \text { '. ابدأ من القسم الأوسط على الورقة. لماذا من الوسط ؟ لأن البداية من الوسط تعطي } \\
& \text { الحرية إلي العقل لانتشار الى جميع الجهات والتعبير الحروالطبيعي }
\end{aligned}
$$

${ }^{12}$ Tony Buzan, Buku pintar ,Mind Map, (Jakarta: Gramedia Pustaka Utama, 2005), hlm. 6

${ }^{13}$ RatnaWilisDahar, Teori-TeoriBelajar ......, hlm110 
Y. استخدام الصور للفكرة الرئيسية العامة. لماذا ؟لأن الصورة تعبر الكلمات والمعاني و

تساعدنا في استخدام الخيال القياسي. وهي جذابة وبتعلنا للتركيز وبتعل العقل إيجابيا

$$
\text { قيفكر }
$$

"ا. صل بين الصورة الرئيسية ولأفكار الرئيسية والأفكار الفروعية الي هلم جرى. كان العقل

$$
\text { يعمل باستخدام الصلات بين الفروع. ونقوم بصلات الفروع فسهل لنا للفهم والمذاكرة }
$$

ع. ـ ارسم الفروع بالخطوط المنخنية. لماذا ؟ لأن الخطوط والسطور تمل العقل. الفروع المنخنية

$$
\text { والحية كالفروع والأغصان للشجرة واجعل و تسر النظر }
$$

•. استخدم كلمة مفتاح لكل خط. لماذا ؟ لأن كلمة مفتاح واحدة بتعل الخريطة المفاهيم

$$
\begin{aligned}
& \text { مرونة وقوية وهي خرة } \\
& 7 \text { 7. استخدم الصور لجميع الخريطة المفاهيم. لأهما لها كلمات ومعاني كثيرة؛ } \\
& \text { منهجية البحث }
\end{aligned}
$$

أ- مدخل البحث ومنهجه

تستخدم الباحثة بالبحث والتطوير (R\&D)،وهو منهج البحث المستخدم لتحصيل

المنتاجات المعينة ثم تجريبتها من حيث فعاليتها ' . ورأى برغ وغال(Borg and Gall) أن البحث

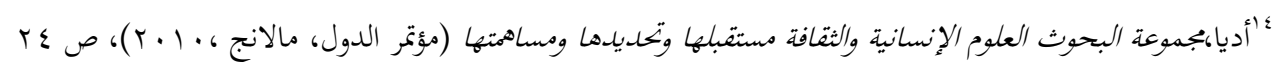

${ }^{15}$ Sugiyono.MetodePenelitianPendidikan, PendekatanKuantitatif, Kualitatif, dan R\&D, . (Bandung :Alfabeta, 2010), hlm 407. 


\section{Rina Dian Rahmawati}

والتطرير هو الإجراءات التي تسيرها الباحثة لتطوير وتصديق المنتج التعليمي '1 . و هذا الشكل

$$
\text { يكون من · · مراحل. (Borg and Gall) }
$$

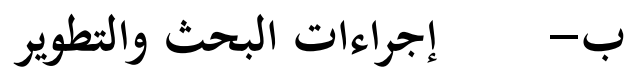

في هذا البحث، تستخدم الباحثة إجراءات التطوير عند برغ و غال وهي على الخطوات

$$
\text { الآتية٪' }
$$

الباحثة تقوم فيه بالدراسة السابقة و ملاحظة الفصل و استعداد تقرير الأول.و دراسة

السابقة محتاجة كأساس في عملة تطوير. ويشمل في الدراسة السابقة المراجع المساعدة مثل

الكتب والمجلات و البحوث السابقة. والملاحظة محتاجة لتنظر الباحثة حقيقة الاحوال في

$$
\text { الميدان كأحوال الطلبة في اجراءات التعليم والتعلم. }
$$

$$
\text { r }
$$

$$
\begin{aligned}
& \text { الباحثة يقوم فيه بصيغة الأهداف الحناصة تعيين المادة والتجربة المبدائية. }
\end{aligned}
$$

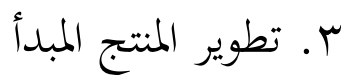

يشمل فيه استعداد المادة التعليمية والالة القويمة.

$$
\text { ع. ـ تجربة المنتج المبدئي }
$$

\footnotetext{
${ }^{16}$ PunajiSetyosari, MetodePenelitianPendidikandanPengembangan (Jakarta: Kencana, 2013), hlm. 222

${ }^{17}$ PunajiSetyosari, ibid. hlm. $237-239$
} 
يشمل فيه تحربة الي ع الطلبة ولنيل المعلومات من المقابلة والملاحظة والإستبانة لتكون

$$
\begin{aligned}
& \text { مداخلات لإصلاحات منتج الأول. } \\
& \text { ه. تفديل المنتج }
\end{aligned}
$$

تفديل المنتج تقوم بها الباحثة أساسا من نتيجة بتربة مبدائية لحصول المعلومات

$$
\text { 7. بحربة الميدانية }
$$

يشمل فيه بتربة و المعلومات الكمية بتمعها الباحثة وتخليلها لتكون مراجعة في

$$
\begin{aligned}
& \text { V. تصديق المنتج التالى } \\
& \text { V تفديل المنتج }
\end{aligned}
$$

تفديل المنتج تقوم بها الباحثة أساسا من نتيجة بتربة ميدانية، والهدف منها لتعيين

$$
\text { م. تجربة الميدان المنتج }
$$

بعد عن قامة الباحثة بالإصلاحات المنتج تستمر بتربته الي جميع الطلبة و مع

$$
9 \text { ـ المعلومات من المقابلة والملاحظة والإستبانة لتكون مداخلات وإصلاحات منتج الأخير }
$$

هذه الإصلاحات تقوم بها الباحثة أساسا من بتربة الميدان الوسعة، وهي معيار

$$
\text { لقياس المنتج على أن يكون صدقا ليقضي مراحل التجربة مرحلة بعد مرحلة }
$$




\section{Rina Dian Rahmawati}

$$
\text { . }
$$

ايصال نتيجة تطوير المنتج إلى المناقشة لأخذ القرارات لكي المنتج المطور يليق في أيدى

$$
\begin{aligned}
& \text { المستخدمين. }
\end{aligned}
$$

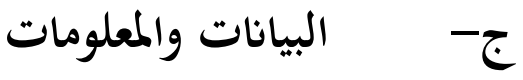

$$
\begin{aligned}
& \text { ( ) (البيانات النوعية } \\
& \text { البيانات النوعية هي البيانات التي تتكون من الكلمات المنطوقة أو المكتوبة } \\
& \text { من المعلم وموظفون في المدرسة المبحوثة والنشاطات من التلاميذ ، وتم الحصول } \\
& \text { علهها بالمقبالة والمالاحظة . } \\
& \text { ( البيانات الكمية }
\end{aligned}
$$

البيانات الكمية تم الحصول علها بالاستبانة. والاستباية تعطي إلى المعلم

$$
\begin{aligned}
& \text { د-أسلوب جمع البيانات } \\
& \text { الذي يعم فيها و التلاميذ الذين يتعلم فيها. }
\end{aligned}
$$

ولحصول على البينات فاستخدمت الباحثة أدوات جمعها كما يلى: الملاحظة , المقابلة

$$
\begin{aligned}
& \text {, الاستبانة ,الاختبار }
\end{aligned}
$$

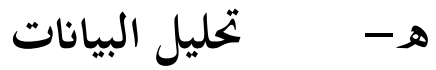

$$
\begin{aligned}
& \text { أ. تحليل البيانات الكيفية } \\
& \text { 1 ـ بأسلوب تحليل المضمون }
\end{aligned}
$$


تطوير المادة التعليمية بخريطة المفاهيم

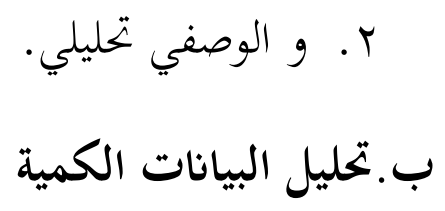

تحليل البيانات من الإستبانة بأسلوب تحليل الإحصائ الوصفي. بأن تكون الباحثة تسجيل البيانات واختيار صحتها ثم ادخال البيانات في الحاسب باستخدام الرموز المناسب. الرموز تحليل نتائج الإستبانة :

$$
p=\frac{f}{n} \times 100 \%
$$

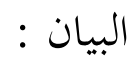

$$
\text { p }
$$$$
\text { f : مجموع الإجابة المعنين لكل سؤال من الأسئلة f }
$$$$
\text { n : بموعة الإجابة علي السؤال }
$$

r. تحليل نتائج الاختبار القبلي و البعدي للطلبة على الرموز

$$
t=\frac{M d}{\sqrt{\frac{\sum x 2}{N} \frac{\mathrm{d}}{(\mathrm{N}-1)}}}
$$

$$
\begin{aligned}
& \text { = Md } \\
& \text { Xd } \\
& \text { N }
\end{aligned}
$$

\footnotetext{
${ }^{18}$ Suharsimi Arikunto, Prosedur Penelitian Suatu Pendekatan Praktek (Edisi Revisi),
} ( Jakarta: PT. Rineka Cipta, 2010), hlm. 85-86 


\section{Rina Dian Rahmawati}

\section{ملخص نتائج البحث}

1. إن المادة المطورة في هذا البحث هى الكتاب التعليمي. وخطوات تطوير هذه المادة

التعليمية تكون على الخطوات المبدئية، والخطوات الإجرائية والتصميم والصدق من الخبراء.

r. أما الخصائص والمميزات من هذا الكتاب هى في كل درس يتضمن قائمة المفردات المتعلقة

بالدرس المدروس ، والمفردات الأساسية يستخدمها بالصور. والقواعد، يستخدمها وفقا

بالمعيار الكفاءة والكفاءة الاساسية. والتقويم، يستخدمه بالتدريبات المتنوعة والمكملة بالألعاب اللغوية.

r. استخدام المادة التعليمية المطورة لدي الطلبة فعالة لتنمية ميولمم في تعليم اللغة العربية
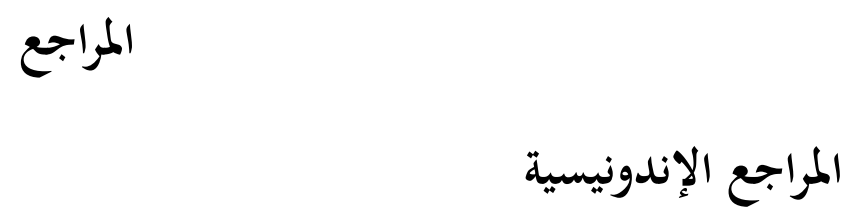

Buzan.Tony.Buku pintar .Mind Map. Jakarta: Gramedia Pustaka Utama. 2005.

Dahar.RatnaWilis. Teori-TeoriBelajar\&Pembelajaran.Jakarta :Erlangga. 2006.

Prastowo.Andi.PanduanKreatifMembuatBahan Ajar Inovatif.Jogjakarta:Diva Press. 2013.

Setyosari.Punaji.MetodePenelitianPendidikandanPengembangan.Jakarta: Kencana. 2013.

Sugiyono.Metode Penelitian Pendidikan, Pendekatan Kuantitatif, Kualitatif, dan $R \& D$.Bandung :Alfabeta .2010.

https:// teachingstrategies/a-map-of-the-concepts-in-education 
تطوير المادة التعليمية بخريطة المفاهيم

$$
\begin{aligned}
& \text { المراجع العربية } \\
& \text { طعيمة. رشدى أحمد.دليل عمل في إعداد المواد التعلمية لبرامج تعلمم العربية. مكة: جامعة أم } \\
& \text { القرعى.01919. } \\
& \text { الناقة. محمود كامل ورشدي أحمد طعيمة. الكتاب الأساسي لتعلم اللغة العببية للناطقين بلغة }
\end{aligned}
$$

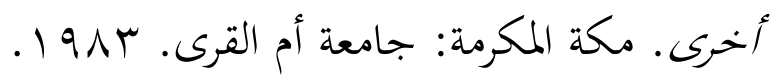

$$
\begin{aligned}
& \text { أديا. مجموعة البحوث العلوم الإنسانية والثتافة مستقبلها وتحايلها ومساهمتها .مؤتمر الدول: }
\end{aligned}
$$

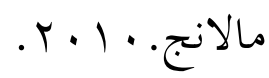

سيتي إيمانية المفلحتين، استخادام إستراتيجية خرائط المغاهيم (mind mapping) في تعلم مهارة

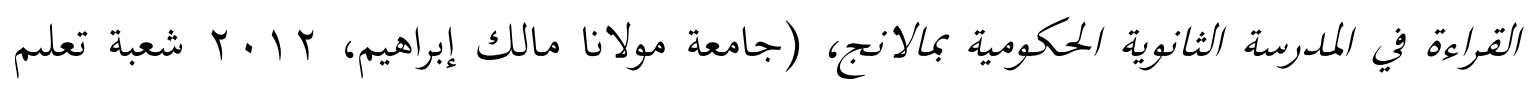
اللغة العربية 


\section{Rina Dian Rahmawati}

122 | Dinamika Vol. 2, No. 2, Desember 2017 